\title{
Detecção de Pyricularia grisea em Sementes de Cevada Produzidas em Sistema Irrigado por Pivô Central no Cerrado Brasileiro
}

\author{
Augusto P. Goulart ${ }^{1}$, Renato F. Amabili ${ }^{2}$, Luiz C. B. Nasser ${ }^{2} \&$ Marcos A. Freitas $^{2}$ \\ ${ }^{1}$ Embrapa Agropecuária Oeste, Cx. Postal 661, CEP 79804-970, Dourados, MS, e-mail: goulart@ cpao.embrapa.br; \\ ${ }^{2}$ Embrapa Cerrados, Cx. Postal 08223, CEP 73301-970, Planaltina, DF
}

(Aceito para publicação em 01/07/2003)

Autor para correspondência: Augusto César Pereira Goulart

\begin{abstract}
Detection of Pyricularia grisea on barley seeds produced under central pivot irrigation in the Brazilian Cerrado

Occurrence of Pyricularia grisea on barley (Hordeum

vulgare) seeds produced under central pivot irrigation is reported for the first time in the Brazilian Cerrado, DF, Brazil.
\end{abstract}

As sementes de cevada (Hordeum vulgare L.) assumem um importante papel na disseminação de inúmeros patógenos causadores de doenças, visto que, do ponto de vista de sanidade, além de sofrerem ataque de inúmeros agentes fitopatogênicos, as sementes podem servir de fonte de inóculo para cultivos posteriores, como também se constituir em veículo para introdução de patógenos em áreas livres de determinadas doenças. Dentre os patógenos associados às sementes de cevada, os fungos constituem o mais importante e numeroso grupo, merecendo destaque Bipolaris sorokiniana (Sacc.) Shoem., Drechslera teres (Sacc.) Shoem. e Fusarium graminearum Schwabe, agentes causais de importantes doenças deste cereal no Brasil (Barba et al., Fitopatol. Bras. 27:389-394. 2002).

Em Outubro de 2001, 35 amostras de sementes de cevada das cultivares BRS 180 e BRS 195, provenientes do Distrito Federal, foram analisadas quanto à sanidade pelo método do papel de filtro + 2,4-D ("blotter test" - incubação por sete dias; fotoperíodo de $12 \mathrm{~h}$ de luz/ $12 \mathrm{~h}$ de escuro; $22{ }^{\circ} \mathrm{C}$ ), no Laboratório de Fitopatologia/Patologia de Sementes daEmbrapa Agropecuária Oeste, em Dourados, MS. O fungo P. grisea foi detectado em $71,4 \%$ das amostras analisadas, em níveis relativamente elevados e até então nunca registrados em sementes de cevada. A média de incidência desse fungo nas sementes foi de $10,2 \%$, atingindo valores máximos de até $34,5 \%$. Os esporos obtidos das sementes de cevada mediram $25,8 \times 12,6 \mu \mathrm{m}$, sendo estas dimensões semelhantes às descritas na literatura para este patógeno. Diferentemente do que ocorre no trigo (Triticum aestivum L.) (sementes infetadas por $P$. grisea apresentam-se enrugadas, pequenas e com baixo peso específico - Goulart \& Paiva, Embrapa Agropecuária Oeste, Boletim de Pesquisa, nº, 31p. Ago 2000), as sementes de cevada infetadas com este patógeno apresentaram-se aparentemente sadias, sem sintomas visíveis e de tamanho normal. Desse modo, a presença desse patógeno nas sementes de cevada nos níveis encontrados, evidencia a possibilidade da introdução dos mesmos em áreas novas. Assim, na impossibilidade do uso de sementes sadias, o tratamento destas com fungicidas eficientes é recomendável, como uma das estratégias na redução da fonte de inóculo primário desta doença e para o manejo sustentável do sistema de produção de cevada irrigado no cerrado. Pyricularia grisea já foi relatada anteriormente causando mancha foliar em cevada, em condições naturais, no Distrito Federal (Anjos \& Charchar, Fitopatol. Bras. 25:205. 2000), em espigas de cevada na região do planalto do Rio Grande do Sul (Casa et al., Anais do $7^{\circ}$ Simpósio Brasileiro de Patologia de Sementes: Resumos e Palestras, p.75. 2002) e em sementes produzidas no Rio Grande do Sul (Picinini; Fernandes \& Pierobom, Comunicação Pessoal, 2002). Porém, este é o primeiro relato da ocorrência de $P$. grisea em sementes de cevada produzidas em sistema irrigado por pivô central no cerrado brasileiro, no Distrito Federal.
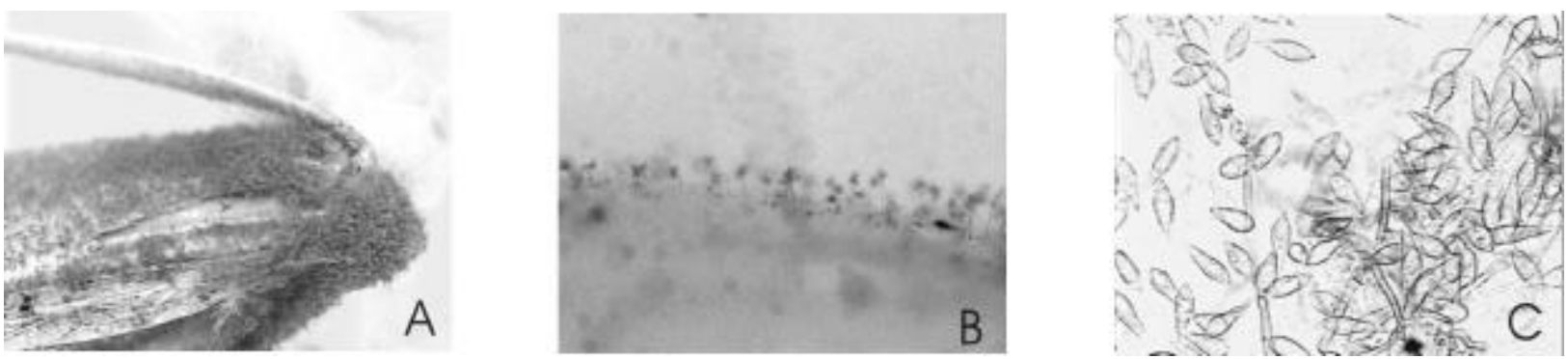

FIG.1 - Pyricularia grisea em sementes de cevada (Hordeum vulgare): (A) semente infetada; (B) detalhe de esporulação do patógeno; (C) conídios e conidióforos do fungo. Fotos: Carlos Pierobom (UFPel - Pelotas, RS) 